\title{
DRUG ABUSE PREVENTION FOR HIGH-RISK AFRICAN AMERICAN CHILDREN AND THEIR FAMILIES: A REVIEW AND MODEL PROGRAM
}

\author{
VINCENT B. VAN HASSELT, MICHEL HERSEN, and JANE A. NULL \\ Center for Psychological Studies, Nova University \\ ROBERT T. AMMERMAN \\ Western Pennsylvania School for Blind Children
}

OSCAR G. BUKSTEIN and JANICE MCGILLIVRAY

University of Pittsburgh

ANDREA HUNTER

University of Michigan

\begin{abstract}
In this article we are specifically concerned with the familial and socioeconomic factors that contribute to the exceedingly high prevalence rates of drug abuse in African-American children. In addition to detailing the impact of drug abuse in African-American children and their families, we consider how this critical health problem can be prevented using existing knowledge and strategies known to mental health professionals. A model program entitled Project for a Substance Abuse-Free Environment (SAFE) is outlined. Its objectives are to implement: (a) a broad-spectrum family intervention to empower disadvantaged and high-risk families in their communities; (b) a competency-based skills intervention to increase resilience and decrease drug use and other maladaptive behaviors in at-risk children; (c) alternative activities that will promote self-efficacy, achievement, and self-esteem; (d) a culturally-relevant evaluation plan that includes both formative (process) and summative (outcome) evaluation; (e) a comprehensive approach for assessing project impact; (e) systematic procedures for enhancing the maintenance and generalization of gains in participating children and families.
\end{abstract}

One of the first federal initiatives in the United States specifically designed to examine the health problems of racial-ethnic Americans was the creation of the Task Force on Black and Minority Health by the Secretary of the Department of Health and Human Services in 1984. The Task Force was "conceived in response to a national paradox of phenomenal scientific achievement and steady improvement in overall health, while at the same time, persistent, significant health inequities exist for minority Americans" (p. 2). The Task Force has been a major impetus for subsequent epidemiological and sociological research focusing on problems of African Americans. These efforts have been summarized by Bell (1991), who concluded that "every issue on the black agenda today - employment, education, crime, housing, healthcare, teenage pregnancy is affected in some way by substance abuse" (p. 1). This contention echoes earlier writings by Harper (1976) and others, who argued that alcohol and drug abuse are the most serious health problems faced by African Americans. There is now a convergence of evi-

Reprint requests should be sent to Vincent B. Van Hasselt, Center for Psychological Studies, Nova University, 3301 College Avenue, Fort Lauderdale, FL 33314.

This study was supported in part by the Center for Education and Drug Abuse Research (CEDAR), funded by the National Institute on Drug Abuse (No. DA05605) research, and contract (No. OE2063) funded by Drug Free Schools and Community's Act. The authors wish to express their appreciation to Tracey Eck and Lynn Greiner for their technical assistance in preparation of this manuscript. 
dence demonstrating that African Americans are clearly at greater risk than most other populations for the all-encompassing deleterious consequences of both alcoholism and drug abuse (e.g., pulmonary disease, hypertension, malnutrition, liver cirrhosis, birth defects, and drug-addicted infants; see King, 1985; Oetting \& Beauvais, 1990; Watts \& Wright, 1983). Moreover, relative to whites, African Americans are much more likely to be arrested for drunkenness, incarcerated for alcohol-related crimes, and victims of alcohol-related homicide (Dawkins, 1980). And while African Americans comprise less than $12 \%$ of the American population, they account for nearly half of all heroin-related emergency room admissions and 30\% of heroin-related deaths (Bell, 1991).

Acquired Immune Deficiency Syndrome (AIDS) also is a severe problem among African Americans due to intravenous (IV) drug use. Indeed, despite their relatively low representation in the general population, African Americans account for a disproportionate $27 \%$ of all persons afflicted with AIDS. Of these cases, $44 \%$ reported injection of an illicit substance prior to diagnosis with AIDS (Center for Disease Control, 1989).

In the succeeding sections of this article we will examine in some detail how substance abuse impacts on African-American children. We next look at the familial and socioeconomic variables in African-American families as they relate to substance abuse. This is followed with discussion as to how substance abuse can be prevented in AfricanAmerican children. Highlighted is a comprehensive description of a model program entitled Project for a Substance Abuse-Free Environment (SAFE), designed to combat the negative influences in the African-American child's milieu. The object in this program is to empower the child and provide him or her with strong alternative choices that will enhance self-esteem. This program is now in place but awaits empirical evaluation and confirmation.

\section{SU BSTANCE A B USEA NDA FR I C A N A M ER I C A N C H I L D R E N}

The problem of substance abuse in African-American children and youth has become the issue of perhaps greatest concern to the African-American community. However, surprisingly few systematic investigations on substance abuse in this population have been carried out (see Atkins, Klein, \& Mosley, 1987; Harper, 1988). A perusal of the work that has been conducted to date reveals an interesting contradiction: African-American youth, who have been described as suffering more than other groups from the problems of substance abuse, generally have lower rates of alcohol and illicit drug use (e.g., Maddahian, Newcomb, \& Bentler, 1988; Newcomb, Maddahian, \& Bentler, 1986). For example, according to the 1985 National Household Survey, lifetime marijuana use is similar among African-American and Latino youth (19.4 and $19.6 \%$, respectively), but higher among whites. On that same survey, $2.9 \%$ of AfricanAmerican youth reported having used cocaine at least once, compared with $5.1 \%$ of whites.

Several reasons have been offered for the aforementioned findings. First, there is a consensus that school-based surveys underestimate substance use by minorities because these individuals have high drop-out and truancy rates and are simply not surveyed. This is important in light of data revealing that over one-third of 18-to 19-year-old African-American youth have dropped out of school (National Institute on Drug Abuse, 1988). And numerous investigations have documented the higher levels of drug use in dropouts (Bruno \& Doscher, 1979; Kandel, 1975; Winburn \& Hays, 1974). Second, with regard to alcohol use, results from general population and school-based surveys 
show that drinking begins later in African-American youth than among white counterparts. Therefore, figures for African-American youth, based on surveys targeting younger age groups, will yield lower percentages than other groups.

The third, and perhaps most important, explanation for lower rates of substance use in minority youth is the fact that national surveys are evaluating persons who do not reside in ghettos. Consequently, these findings are inaccurate and misleading because the highest rate of drug use occurs in the most severely economically disadvantaged areas. As Oetting and Beauvais (1990) cogently point out:

... drug problems of minorities in disadvantaged environments probably do not generalize to minority youth in other environments. In ghettos, barrios, or Indian reservations, prejudice is compounded by social isolation, poverty, unemployment, deviant role models, and sometimes by gang influence. The result includes heavy drug involvement, but these pockets of high minority drug use probably are not well represented in general population surveys and are not typical of other American minority youth. (p. 391)

\section{SU B S T A N C E A B U S A A D T H E AFR I C A N-A MER I C A N F A M I L Y}

Let us now consider the relationship between substance abuse and the AfricanAmerican family. Parents and families have been the focus of increased investigative attention over the past decade with regard to their (a) ability to provide security, affirmation, emotional comfort, and personal growth (Berkowitz, 1982; Weiss, 1974); (b) utility in serving as primary role models for coping, problem-solving, and interpersonal skills (Forehand et al., 1991; Hops et al., 1990); (c) provision of consistent and reliable monitoring and supervision, and reasonable behavioral consequences; and (d) use of extreme aversive forms of child management (i.e., child abuse and maltreatment). In discussing the problem of adolescent alcohol and drug abuse, Kaufman and Borders (1984) state that "a healthy family system will prevent adolescent substance abuse even in the face of heavy peer pressure to use and abuse drugs. As warm and mutual family ties diminish, the adolescent becomes more vulnerable to peer pressure" (p. 366). This position also has been taken by Hawkins, Lishner, and Catalano (1985), who underscore the necessity of establishing "strong bonds to family and school" in order to decrease the likelihood of affiliations with drug using peers.

According to Kandel (1982), three parental variables have high predictive power for the initiation of adolescent substance abuse: (a) parent drug using behaviors, (b) parental attitudes concerning drugs, and (c) the quality of parent-child interactions. The latter factor has been characterized by lack of family closeness (Brooks, Linkoff, \& Whiteman, 1977), low levels of maternal involvement in activities with children, and insufficient, inconsistent, or severely harsh parental discipline (Baumrind, 1985). Similarly, investigations by Dishion and his colleagues at the Oregon Social Learning Center (Dishion, Patterson, \& Reid, 1988; Dishion, Reid, \& Patterson, 1988) have highlighted the importance of effective behavior management practices in reducing adolescent substance use. Results of their program of research have documented the effects of poor parental monitoring/supervision, inadequate family problem solving and coping skills, and high levels of family conflict and coercive interchanges on subsequent adolescent substance use and abuse.

In a discussion of substance use in African-American families, Lipscomb and Goddard (1984) contend that this family system historically has been viewed as "a deviant, 
pathological social organization that is unable to perform its major responsibility of preparing new members for their places as currently constituted in society ... 'this missocialization' manifests itself in low academic motivation, juvenile delinquency, crime and deviant social behavior, drug and alcohol use and abuse, etc." (p. 338). However, as they astutely point out, such characteristics have been assigned on the basis of prejudicial and unfounded racial stereotypes. Indeed, numerous investigators (e.g., Billingsley, 1968; Shimkin, Shimkin, \& Frate, 1978; Wilson, 1989) have identified a multitude of strengths in African-American families. Some of these include strong achievement motivation, kinship ties, and work and religious orientation.

While earlier formulations and generalizations of the African-American family as dysfunctional units have since been dispelled, there are several factors that place many of them at risk for a range of difficulties. First, it has been estimated that approximately $35 \%$ of African-American families live at or near the poverty level. Second, 33\% of African-American children (compared to $14 \%$ of white children) have no working parent in the household. In addtion, $62 \%$ of African-American adults who are parents are divorced, separated, widowed, or never married, as opposed to $33 \%$ of white adults; $58 \%$ of African-American births are to unmarried mothers as opposed to $11 \%$ of white births; and $28 \%$ of African-American births are to adolescents as opposed to $14 \%$ of white births (see Glick, 1981; Jorgensen, King, \& Torrey, 1980; Reid, 1982). Poverty, in combination with racism, discrimination, and poor self-esteem can have profound harmful effects for family functions and child and adolescent development.

Poverty is most evident among African-American single-parent families. In fact, nearly $53 \%$ of these families have been classified as poor (Reid, 1982). This is significant given the causative role of poverty in chronic stress, low self-esteem, social isolation, and feelings of hopelessness, loneliness, and helplessness (Belle, Longfellow, \& Makosky, 1982; Gephart \& Pearson, 1988; Tienda \& Angel, 1982). There also is an accumulation of evidence showing that poverty reduces a person's repertoire of available adaptive coping resources (see Albee, 1982). Moreover, poverty and its concomitant features (e.g., crowding, inadequate housing) have been implicated in family violence, particularly child physical abuse and neglect.

While child maltreatment is epidemic in society as a whole, African-American children are over-represented in reported cases of abuse and neglect. In 1986, 34\% of reported cases of maltreatment involved African-American families (American Association for Protecting Children, 1988). Although less likely to be sexually abused, relative to other populations, African-American children are more often injured secondary to physical abuse. In general, unemployed, single females, who are economically disadvantaged, experience greater stress, and report symptoms of depression, are at high risk for neglecting their children. Child abuse and neglect must be viewed within the larger context of a violent environment. Children and adolescents may be further exposed to spouse batteries, elder abuse and neglect, psychological or emotional abuse, neighborhood crime, and/or gang violence. Taken together, African-American, innercity youth are at great risk for victimization via the experience or observation of violence.

As a result of the marriage and childbearing patterns of African-American parents and the prevalence of extended family households, African-American children also are likely to experience a diversity of family structures (Hofferth, 1984; Hunter \& Ensminger, 1991). The household family units in which children live are embedded in an extended kinship system that provides a cultural framework within which patterns of 
childrearing and family interaction are developed and evaluated. It is also a primary context in which networks of reciprocal obligation and support are established and maintained (e.g., Martin \& Martin, 1978; Shimkin et al., 1978; Stack, 1974). Several studies have noted that African-American kin networks are sources of social support (e.g., Dressler, 1985; McAdoo, 1978; Stack, 1974; Taylor \& Chatters, 1986) and may mediate risks associated with early childbearing (Stevens, 1984), provide childrearing support for single parents (e.g., Wilson, 1989), and act as a mechanism to share or pool economic resources for those in poverty or near poverty (e.g., Hofferth, 1984; Stack, 1974; Tienda \& Angel, 1982). Thus, the demography of African-American households (as defined by parental status) should be viewed in juxtaposition to the extended kin group and non-nuclear household structures.

Recent studies with African-American single-parent families have examined the supportive and beneficial effects of the extended family (Wilson, 1989; Wilson \& Tolson, 1990). Work in this area has shown that involvement of extended-family members facilitates the mothers' participation in self-improvement activities, increases the quality of child care, and reduces possible negative effects of single parenting (e.g., neglect, physical abuse, inadequate nutrition, insufficient supervision). African-American extended family households are likely to include grandmothers (Beck \& Beck, 1984, 1989; Hunter \& Ensminger, 1991; Martin \& Martin, 1978). The level of parenting involvement of coresidential grandmothers varies by family structure (Wilson, 1989). Grandmothers in mother-absent and single-parent households are more likely to be involved in primary parenting activities (i.e., supportive, rule setting, and punishing). Grandmothers appear to serve as excellent role models for effective caregiving as reflected by their reports of more responsive and less aversive interactions with their infant grandchildren compared to their daughters (see Stevens, 1984). The reciprocal nature of the mother-grandmother relationship is highlighted by the former reporting that they feel supported in their role as parents (Field et al., 1980). Finally, results of studies by Kellam and his associates reveal improved long-term achievement, enhanced social adjustment, and participation in fewer deviant activities (e.g., substance abuse, criminal acts) in children residing in single parent households where an extended family structure is available (Kellam, Ensminger, \& Turner, 1977; Kellam et al., 1982).

The prior discussion highlights the important protective and insulative function of the family in children at risk for substance abuse and other problem behaviors. Yet, despite the integral role of the family unit, most large-scale efforts attempting to decrease or delay the onset of substance use or abuse in high-risk children and youth have failed to include the family system in their intervention efforts. The need for family-oriented interventions in substance abuse prevention is discussed by DeMarsh and Kumpfer (1986). "Since the family is heavily implicated in substance abuse ... prevention interventions aimed at strengthening the family's role in socializing the child to be a productive member of society will decrease substance abuse" (p. 121). Hawkins et al. (1986) concur that, given the consistent findings concerning the effects of the quality and consistency of family management, family communication, and parental role modeling on children's substance abuse, prevention programs attempting to prevent or delay onset of substance use must include a focus on the family.

Intervention based on data from schools seems particularly relevant given the influence of school factors on high-risk status. For example, from age 9, academic failure and misbehavior in school predicts later delinquent behavior (Fleming, Kellum, \& Brown, 1982). Truancy is also a predictor for later delinquent offenses. Unfortunately, 
African-American children frequently live in social environments that make them less likely to perceive the benefits of high educational achievement (Ogbu, 1986). Teachers appear to have lower expectations for the academic performance of African-American children (Rist, 1970). These factors may account for the substantial gaps in achievement scores between white and African-American children and the greater delinquency rate in African-American children (Elliot \& Ageton, 1980). School factors may be significantly influenced by family factors as families with a low-achieving child are characterized by feelings of depression, lack of personal control, and low emotional spirit (Clark, 1983). Therefore, prevention interventions designed to influence the highrisk factors of school behavior and academic performance need to have a significant family component.

In summary, there appear to be significant levels of identified risk factors for substance use and abuse in African-American children and their families. Poverty, abuse and neglect, poor academic performance, and delinquency are all salient, interdependent risk factors requiring concurrent intervention in any realistic prevention project.

\section{PREVENTION OF SUBSTANCEABUSE I N A F R I CA N- A M E R I C A N C H I L D R E N}

What then can be done to prevent substance abuse in African-American children? It is true that most extant prevention programs have been directed toward white individuals (see reviews by Prendergast, Austin, Maton, \& Baker, 1990; Schaps et al., 1981). Of those that have included high-risk African-American children, many "that are being implemented in the inner city were originally designed for middle-class white youth and, as such, are replete with middle-class values and biases. Although the need for culturally specific approaches to effective intervention has been acknowledged for some time, and indeed some curricula have been adapted for the recipients, the issue has not been given the consistent, serious scholarship it deserves" (Rhodes \& Jason, 1990, p. 396).

There are several possible reasons for the lack of prevention programs with high-risk inner city children. First, aside from descriptive studies, scientific knowledge concerning etiological factors in African-American children's substance use is scarce (Prendergast et al., 1990). Prevention specialists are likely to be wary about applying strategies to this population until comprehensive epidemiological data are garnered. However, as Holden et al. (1990) warn, "To not aggressively research effective interventions for preventing black Americans' substance abuse . . . appears neither responsible nor ethical in the face of serious and growing drug and alcohol use among future generations of this country's largest ethnic-racial minority population" (p. 874). Second, the high attrition rates that are likely when working with children and youth in the poorest and most crime-infested neighborhoods undoubtedly discourage investigators who are concerned about resultant methodological deficiencies. Indeed, the high drop-out and truancy rates make it extremely difficult for researchers to conduct proposed intervention programs with "methodological purity" (e.g., equal cell size, administration of complete program, regular assessments with most participants).

A related issue is the lack of cooperation from those individuals who are targeted for intervention. Indeed, the immediate and potent reinforcers available to youth residing in impoverished neighborhoods already have been mentioned. To compete with such powerful contingencies, multilevel programming and involvement of significant others 
in the child's environment are necessary. In particular, inclusion of the family or other careproviders appears to be essential for achicving cooperation in implementing behavior change strategies for high-risk, inner city African-American children (e.g., Cowen \& Work, 1988; Hawkins et al., 1986; Werner \& Smith, 1982).

Several current large scale prevention programs have included various racial-ethnic minority subgroups (see Dielman, Shope, Butchart, \& Campanelli, 1986; Pentz et. al., 1989). However, few substance abuse prevention activities that are culturally specific to just the African-American community have been reported in the literature. One exception is "Soulbeat," a project developed as a component of a community substance abuse treatment and prevention center (Maypole \& Anderson, 1987). In this effort, African-American children performed skits and plays (e.g., dramatizations of peer pressure, parent-teen communication problems, institutional racism) in their schools and churches. Rock music, rap, and break dancing were included. A four-session drug education program also was offered. The goals of Soulbeat were to increase drug awareness and to enhance participant's sense of self-confidence and self-worth. While no empirical data were presented, Maypole and Anderson (1987) felt that "a group norm which discouraged drug use" was formed and that Soulbeat involvement became a "prestigious, ego reinforcing experience" for the children. However, four sessions are likely to be insufficient given the competing contingencies to become abusers faced by these children in their natural environments.

In another study, Beaulieu and Jason (1988) administered an 8-week drug abuse prevention program to seventh graders from an inner-city elementary school consisting of all African-American children. This approach combined dissemination of drug-related information with training in problem solving, decision-making, and resisting peer pressure. Several older students also were recruited to serve as peer helpers. Results showed that those receiving the program displayed greater drug knowledge and improved problem solving skills relative to untreated controls.

Losciuto and Ausetts (1988) evaluated the effectiveness of Project PRIDE, a schoolbased affective education program offered in urban Philadelphia to a high-risk population of children in grades 5 through 7 . Twelve weekly student sessions targeted the development of knowledge and attitudes regarding drugs, self-awareness, interpersonal relationships, and life skills (decision-making, problem-solving, and communication skills). Skills training also was provided to parents and teachers to enhance communication, conflict resolution, and behavior management skills. This was accomplished via informal lectures, group discussions, and learning exercises. PRIDE students showed improved attitudes toward drug use and knowledge following participation. In addition, there was a decrease in willingness to experiment with drugs. Further, children reported that they gained significant knowledge and skills from the program. Unfortunately, no significant gains were made on parents' ratings of family environment. Teacher data also reflected minimal attitudinal change as a function of the PRIDE program.

Botvin et al. (1989) applied a 12-session smoking prevention program to students in nine predominantly African-American urban junior high schools. The strategy involved an adaptation of the Life Skills Training (LST) curriculum developed by Botvin and his colleagues in previous research (Botvin et al., 1984; Botvin \& Dusenbury, 1987). In this investigation, LST included information concerning cigarette use and instruction in generic personal and social coping skills to reduce participants' susceptibility to social influences to smoke. In an effort to make this intervention more culturally relevant, Botvin et al. (1989) conducted a review by a committee of African- 
American researchers, junior high school students, and a panel of outside experts to ensure that the program contained material that was "appropriate and relevant" for African-American youth. Results indicated that the program reduced the proportion of students who smoked in a 1-month period by $56 \%$. Knowledge of the negative consequences of smoking also was found to increase.

It is clear to us that to combat the severe disadvantages experienced by many young, inner-city African-American children, only a community-based program that specifically and comprehensively deals with the challenges and difficulties of these individuals will have a chance of success. Moreover, we firmly believe that such a program must provide viable alternatives that have meaning to the children and their care providers and that will enhance their self-esteem in a positive manner. Below we describe Project SAFE, which is specifically designed to compete vigorously with the existing negative elements in the natural environments and community of our targeted children. We contend that federal funds for such a program would represent a far better investment than monies later allocated for conducting remedial work with hard use addiction. The old adage of "an ounce of prevention is far better than a pound of cure" clearly has relevance here.

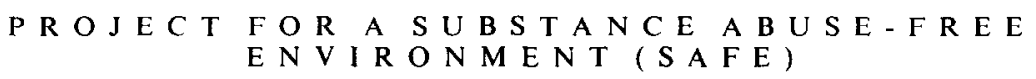

The Project for a Substance Abuse-Free Environment (SAFE) consists of three major elements: (a) Parent and Child Training (PACT) - a family, home-based intervention to improve multiple aspects of family functioning; (b) Peers as Leaders (PALS) - a peer-mediated program to teach and develop stress-protection skills and social competency; and (c) Community Activities Program (CAP) - a program of prosocial activities designed to further develop and practice the competency skills taught in PALS and to expose the child to prosocial behavior and its rewards. Each component is described in more detail below. The three components represent a comprehensive effort to prevent substance abuse in a high-risk population by coordinated interventions against multiple risk factors in the child, his or her family, and their relationship in the community.

\section{Parent and Child Training (PACT) program}

The PACT program is a multiple-component, home-based intervention for at-risk and disadvantaged African-American families. The goals of PACT are to: (a) utilize family strengths to enhance coping and overall functioning; (b) train parents in the use of problem-solving and stress-reduction techniques that can be applied to difficult parent-child or other stressful situations; and (c) empower families to increase use of social and community resources and improve their situation. PACT is implemented in careful coordination with the Peers as Leaders and Community Activities Program (described below) so as to maximize the effectiveness of all three interventions. Similarly, PACT works closely with existing community resources (e.g., churches, community centers) to provide maximum benefit to families and the community. Although the PACT Program specifically targets parents and the participating child, issues and problems involving siblings are also addressed. Indeed, the primary goal of PACT is to promote family adaptation, thus necessitating the involvement of all family members in the intervention. 
PACT consists of nine separate components addressing a variety of areas of possible need in at-risk families. An important aspect of PACT is that the intervention for each family is individually tailored. Only those components that are relevant for the family (as determined by the family and evaluation data) are carried out. PACT is implemented in $16,1 \frac{1}{2}$ to 2 -h sessions that are conducted in the family's home. PACT components are described below.

Parenting skills training. Parenting skills training seeks to assist parents in becoming more effective and nurturing with their child (e.g., Forehand \& McMahon, 1981; Lutzker, Megson, Webb, \& Dachman, 1985). Using a didactic approach, parents are taught how to: (a) be more sensitive to their child's emotional needs; (b) provide for the child's care and nutritional requirements; (c) increase their use of praise and positive social attention; and (d) use positive physical attention (i.e., physical affection). The overall goal of this component is to improve the parent-child relationship, thus providing a foundation for the child's further social, cognitive, and emotional development.

Impulse control training. This component is administered to parents who use extensive physical punishment and/or are at high risk for physical abuse. Here, the parent is trained to reduce or eliminate violent expressions of anger. Also, more efficacious handling of situations that precipitate anger outbursts are emphasized (Denicola \& Sandler, 1980). Impulse control training includes identifying and anticipating events that elicit anger, learning self-control through cognitive-behavioral techniques (e.g., thoughtstopping and cognitive restructuring), and using alternative conflict resolution strategies. Parents practice impulse control skills through role-playing during sessions. Impulse control training is designed to break the cycle of anger and frustration that can lead to abusive behavior. Further, it provides parents with a new behavioral repertoire with which to respond to difficult parent-child situations.

Child management skills training. Child management skills training is designed to teach parents to be more effective in controlling their child's maladaptive behaviors, including noncompliance, oppositionalism, and conduct problems. Parents are trained to use techniques of positive reinforcement, differential reinforcement, extinction, and time-out. Concrete examples and specific child behavior problems are presented, and appropriate management techniques specifically designed to remediate these difficulties are taught. Parents rehearse newly acquired skills within the session, and then practice them in between counselor visits. Also, in vivo coaching is carried out to promote maximum learning of principles and techniques. In addition to reducing child behavior problems, this component is designed to increase positive parent-child interactions and strengthen parent-child bonding.

Household organization and safety training. This component is designed to reduce stress and ensure that a disorganized or unsafe household does not interfere with other aspects of parenting and family life. Implementation of this protocol includes teaching the specific skills needed to effectively organize the household. Areas targeted include meal planning, daily schedules, money management, keeping physician appointments, coordinating shopping trips, and promoting home safety strategies to prevent accidents (Barone, Greene, \& Lutzker, 1986). 
Stress reduction training. This component, in combination with problem-solving skills training below, focuses on increasing relaxation skills, enhancing coping, and reducing stress. Parents are taught one of the several relaxation techniques (Poppen, $1987)$ to induce deep-muscle relaxation. Relaxation skills are taught in sessions, and parents are encouraged to practice them between meetings with the assistance of audiotaped instructions. Once relaxation has been mastered, parents are instructed to use these newly acquired skills during stressful situations, including problematic parent-child interactions, family disagreements and arguments, and other day-to-day difficulties.

Problem-solving skills training. Problem-solving skills training consists of teaching parents specific strategies in coping with a variety of life stressors and daily problem situations. Aspects of this component include: clearly defining the problem, generating solutions, planning a response, carrying out the response, and evaluating effectiveness of the response (Spivack, Platt, \& Shure, 1976).

Social skills and assertion training. The purposes of this component are to teach parents skills that will help them network with available community resources, expand their social circle in an effort to enhance social support, and work with social service and other agencies to obtain needed services. As in the other components, social skills and assertion training are individually tailored depending on parental and family needs. Skills are taught in a didactic manner, and parents role-play interactions involving initiating conversations, maintaining conversations, asking for help and assistance, and standing up for one's self (or the child and family).

Leisure and play skills training. The effective use of leisure time is critical to reducing stress and strengthening bonds among family members. Often, however, high-risk families experience great difficulties in setting time aside for individual or family life. This component involves working with parents to set aside leisure time, and plan activities for themselves and their families that are both rewarding and relaxing.

Psychodevelopmental education. Psychodevelopmental education consists of teaching parents about social, cognitive, and emotional development in pre-adolescents. The purposes of this component are to foster parental understanding of their child's development, and promote normal expectations for their child's behavior. Family intervention programs in this age group typically ignore developmental issues. Psychodevelopmental education is drawn from several standard texts on this topic.

\section{Peers As Leaders (PALS) program}

The aim of PALS is to provide stress-protective skills that have been implicated as requisite to resilience and invulnerability to stressful life events and circumstances in high-risk children (Cowen \& Work, 1988). This strategy is, in part, an adaptation and integration of previously described general life skills and social competency-based programs (e.g., Botvin \& Wills, 1985; Pentz et al., 1986; Schinke \& Gilchrist, 1984). These have typically included some combination of approaches to improve decision-making, self-change and self-improvement, skills for resisting peer pressure, and techniques to cope effectively with anxiety. However, few such programs have been utilized with elementary school-aged students (Church et al., 1990; Dielman et al., 1986; Jones et al., 1990). And with rare exceptions (Beaulieu \& Jason, 1988; Maypole \& Anderson, 1987), 
little attention has been directed to implementation of skills-based approaches with young African-American children.

PALS involves five major elements: (a) substance use information; (b) social skills training, (c) problem-solving skills training; (d) self-control training; and (e) academic tutoring and homework monitoring. These activities are conducted after school in space provided at each child's school setting. Training is carried out by high-school-age students from the targeted children's community, who are recruited to serve as Peer Leaders on the basis of high academic achievement and social status in their own schools.

Substance use information. The major goal of this phase of PALS is to influence drug knowledge and attitudes in participating children. This component consists of didactic presentations and discussions of the following: defining and giving examples of drugs, types of drugs, addiction, drug use, drug abuse, legal and illegal drugs, pushing or dealing drugs, consequences of drug abuse, and rules to prevent drug abuse. The latter involves identifying: (a) antecedents or situations where drug offers or abuse are likely; (b) consequences of drug abuse; and (c) determining ways of having a good time without drugs. Also covered are common attitudes and beliefs about alcohol and drugs, social influences affecting decisions to not use/use drugs, and media influences on substance abuse behavior.

The above mentioned are taught through a combination of stories, films, and presentation of various drug-related scenarios. Peer Leaders are also trained to employ behavioral procedures (feedback, modeling, rehearsal, role-playing, and social reinforcement) in their instructional efforts.

Social skills training (SST). A considerable body of research has shown that children who exhibit pro-social behavior: (a) receive increased social reinforcement from their peers; (b) perform better in academic, social, and emotional realms; and (c) engage in relatively low rates of maladaptive behavior (e.g., substance use, antisocial acts; see Hartup, 1992; Van Hasselt, Hersen, Whitehill, \& Bellack, 1979). Moreover, this positive cycle is perpetuated through adolescence and perhaps adulthood, creating a reciprocal interpersonal environment over the lifespan. Conversely, children who are characterized by social skill deficits (passive, isolated, aggressive) engage in fewer positive social interactions, thus resulting in fewer social reinforcers from their environment. For children who are besieged by opportunities and offers to engage in substance use, the ability to deny these and extricate themselves from high-risk situations is critical.

The objective of SST is to train children in specific behaviors related to the following areas of social interaction: (a) conversational skills - initiation of social contacts and conversations, and making friends; maintaining interpersonal exchanges; (b) positive assertion skills - expression of positive feelings, such as affection, agreement, approval, giving and receiving compliments, and making apologies when appropriate; (c) negative assertion skills - denying unreasonable or inappropriate requests (e.g., offers to use alcohol or drugs), avoiding mistreatment, and standing up for one's rights. Other topics covered in SST are empathic skills, social perspective taking, recognizing the rights of others, and dealing with aggressive behavior, teasing, rejection and disappointment, group pressure, decision-making, and authority figures.

To develop program goals, PALS Leaders conducting SST utilize direct instructions, performance feedback, modeling, behavior rehearsal, shaping, fading, social reinforcement, and homework assignments. In addition, a series of scripts involving situations 
in each of the three above-mentioned topic areas is presented. These scripts provide children with the opportunity to experience and role play (with each other and the Peer Leader) the various social situations about which the Peer Leader provides feedback and modeling. Behavioral homework assignments give children the opportunity to practice their newly acquired interpersonal skills in a variety of naturalistic settings.

Problem-solving skills training (PSST). Psychosocial models of vulnerability and psychopathology have implicated social problem solving deficiencies as an important mediator of abnormal behavior in children, adolescents, and adults (Dodge, 1980; Dodge \& Newman, 1981; Goldfried \& D'Zurilla, 1969; Joffe et al., 1990; Spivack et al., 1976). For example, within the area of depression, research has supported a link between depression and poor social problem-solving skills (Nezu, Nezu, \& Perri, 1989). Further, there is evidence that a key deficit in drug abusing, suicidal, and aggressive populations is inadequate interpersonal problem-solving (Carey \& Carey, 1990; Clum, Patsiokas, \& Luscomb, 1979; Richard \& Dodge, 1982). Specifically, it appears that persons with poor problem-solving skills, under high levels of stress, lack the coping ability to generate and implement effective solutions to relieve stress. Failing to find effective solutions, these individuals become hopeless, emotionally and socially dysfunctional, and in some cases, turn to drugs or even suicide (Schotte \& Clum, 1987).

In the present project, problem-solving skills are trained through a series of activities that promote development of the following processes: (a) definition of problem; (b) generation of alternatives; (c) evaluation of consequences; and (d) evaluation of solutions. The major objective is to teach children a simple, logical, and generalizable problemsolving sequence that will enable them to solve their own problems. This is possible once they are provided (through PSST) with the cognitive processes and mechanisms that they can incorporate into their interpersonal repertoire as a means of facilitating their own problem-solving abilities.

PSST involves activities or tasks that are focused on controlling anger, improving attention skills, and dealing with irritation, frustration, and delay of gratification. Activities are presented in each session that promote understanding and growth in each of these areas from a problem-solving orientation. Issues (e.g., anger, frustration) encountered outside of sessions are illustrated and discussed, and appropriate direction and problem-solving strategies are provided by the PALS Leader. There is an emphasis on children's understanding of how and why particular situations have occurred, associated feeling states, and possible solutions and consequences in problem or conflict resolution.

Self-control training ( $S C T$ ). The social learning transactional model of resiliency is based, in part, on Bandura's $(1977,1988,1989)$ self-efficacy theory of behavior. Selfefficacy refers to "people's beliefs about their capabilities to exercise control over events that affect their lives . . . people's self-efficacy beliefs determine their level of motivation, as reflected in how much effort they will exert in an endeavor and how long they will persevere in the face of obstacles" (Bandura, 1989, p. 1175-1176). According to this perspective, individuals can effect change in themselves and their situations through their own efforts. This ability is particularly important for persons encountering chronic and pervasive stressful life situations where external support and reinforcement may be minimal or nonexistent.

Over the past decade, considerable behavioral research has focused on strategies for 
increasing self-efficacy and motivation through SCT. This involves the training of selfmanagement skills via instruction in three techniques: (a) self-monitoring - self-observations of one's level of performance or functioning in a particular area or skill; (b) selfevaluation - setting self-goals and assessing whether one has adequately achieved them by comparing them with a pre-determined standard; (c) self-reinforcement - arranging reinforcement contingencies for attaining one's goal and self-administering reinforcement once the objective is met.

Self-control strategies have been utilized with a variety of child populations and problems (e.g., depression, aggression, social isolation, hyperactivity; see reviews by Jones, 1988; Kaslow \& Rehm, 1983). In PALS, participants receive individually tailored instruction in self-control strategies that enables them to: (a) observe their own performance in specific areas of difficulty, deficit, or interest (e.g., academic coursework, homework completion, social interactions with peers or adults, athletic skills) (selfmonitoring); (b) set specific goals that they would personally like to achieve in one or more of these areas and develop an action plan (self-evaluation); and (c) reward themselves for accomplishments (self-reinforcement).

As per Bandura's contentions, self-control strategies should have considerable heuristic value in increasing children's: (a) level of motivation in targeted areas; (b) sense of self-competence, self-esteem, and self-efficacy/mastery; and (c) internal locus of control (i.e., the realization that things that happen to them are a function of their own actions and not external factors). Further, SCT is a cognitive process; thus, it involves acquisition of a set of skills that are "transportable" and generalizable across life areas and over time.

Academic tutoring and homework monitoring. In light of previous findings relating early academic failure to a wide range of subsequent adjustment problems (Elliot \& Ageton, 1980; Fleming et al., 1982), this aspect of PALS focuses on improving children's attention and performance in academic areas. Specifically, Peer Leaders spend some portion of each session reviewing current coursework and homework assignments. Questions or problems that children are having are discussed, and Peer Leaders assist them in working through areas of difficulty. Peer leaders also positively reinforce academic success.

Further, Peer Leaders coordinate with children's teachers and parents with regard to homework assignments on a regular basis. Through this approach, Peer Leaders are able to systematically monitor children's homework accuracy and completion. Problems that participants are having with homework are also addressed. Where they are unable to help, Peer Leaders communicate student's needs to their primary teachers and parents who provide additional instruction in the identified problem area.

\section{Community Activities Program (CAP)}

Music. The study of African-American music in the context of its culture offers an alternative to young children who may otherwise focus their attention on drugs or involvement in antisocial activities. A music program of this nature integrates music techniques as well as socio-musicological factors that surround the process of musicmaking. Emphasis is therefore placed on: (a) rhythm and body motion; (b) music with audience participation; and (c) styles of delivery that are unique to the traditions of the African-American church and nonsacred social modes of musical expressions. 
The primary objective of this element is to aid the student in becoming: (a) proficient in the necessary basic skills to perform various styles of African-American music; and (b) capable of performing music of other ethnic origins. In addition, the music program provides basic music instruction which emphasizes the development of aural skills, creativity, and the gradual introduction of basic visual symbols used in contemporary music. (Students who do not develop skills on melodic instruments are encouraged to participate in the playing of percussion instruments.)

Participants also are provided the theory of music that is necessary for effective playing and performance. The level of music theory is based on the level of each student (beginner, intermediate, advanced). The structure of music classes has a classical and jazz-based theory and historical orientation. Each student receives an initial audition to determine their appropriate level of musicianship. Also, history and theory are applicable to their chosen instruments. Students who have never played an instrument are encouraged to express instrument preference. Instruction is provided in basic instrumentation typically used in public school bands. Instruments associated with contemporary music (synthesizers, electric guitars, electric basses, amplifiers) also are made available.

Athletic activities. Project SAFE participants are offered a wide range of athletic activities. These are provided through coordinated efforts involving the local Department of Parks and Recreation and University Athletic Departments. Some of these activities include tennis, football, boxing, weight-lifting, basketball, jogging, swimming, and bowling.

\section{Project SAFE Procedure}

Over the duration of the project, fourth grade students and their families are identified from elementary schools in the Pittsburgh Public School District. The rationale for utilizing fourth grade school children derives from epidemiological evidence suggesting that by this time children who are manifesting significant behavior problems may have already begun on the path toward consolidating and crystallizing the more serious antisocial disorders (Patterson, 1982). Thus, inclusion of older children may raise problems with regard to their difficulties being more intractable, severe, and of a clinical, rather than a subclinical variety. Conversely, the inclusion of very young (pre-fourth grade) children may raise questions as to the actual level of seriousness of and/or stability of their behavior. Use of younger age groups is also more likely to yield false positives in the case of the identification procedure.

From the school district's data base and records, the following risk factors for alcohol and drug abuse are examined: (a) economically disadvantaged; (b) mental health or behavior problems; (c) chronic school failure; (d) victim of physical, sexual, or psychological abuse; and (e) child of a substance abuser. Given the demographic profile of inner-city communities, it is highly likely that almost all children have at least one risk factor. Therefore, students with multiple risk factors (three or more) are identified as high risk and considered for inclusion in Project SAFE. Following identification, these children and their families are approached and asked to participate in the project with adherence to appropriate informed consent procedures.

Each group of participating children and their families enter all three project components (PACT, PALS, and CAP) simultaneously. The PACT component consists of 16, 2-h home-based sessions over a 6-month period while PALS and CAP consist of 2h sessions, twice a week extended over 18 months (see Table 1). 
Table 1. Summary of procedures

STEP

Fourth Grade Children and Families identified as "high risk" through school case management system.

STEP 2

Pre-Intervention Evaluation

STEP 3

\begin{tabular}{|l|}
\hline PACT \\
16 2-hour home \\
sessions over \\
6 months \\
\\
\hline
\end{tabular}

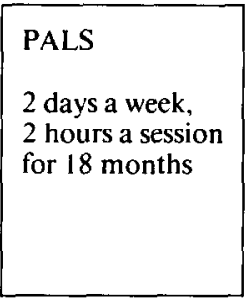

CAP

2 days a week, for 18 months

( 3 days a week during summer vacation)

Saturday a.m.

programming

STEP 4

Post-Intervention Evaluations (see Evaluation Schedule)

\section{Evaluation plan}

Culturally relevant and sensitive evaluation methods must be utilized if the efficacy of an intervention with racial-ethnic minorities is to be examined. Further, the scarcity of assessment materials normed on African-American populations (inner-city poor and otherwise) requires monitoring and evaluation of assessment materials and their validity throughout the evaluation process. Attention to issues of cultural appropriateness must be coupled with the acceptance of the cultural integrity of African-American children and families and their ability to contribute to the ongoing development of the evaluation and prevention strategy.

A Project SAFE Ad Hoc Review Committee consisting of African-American mental health professionals and educators was formed for the purpose of providing a preliminary review of measures proposed for the evaluation plan. The specific goal of the committee was to judge the appropriateness and cultural relevance of the measures for the target population. Of the set of originally proposed instruments, several were eliminated, and suggestions for modifications or revisions of devices that were retained, were made. Described below are those measures that were viewed by the Ad Hoc Committee as most useful and culturally meaningful for participating children and their families.

Self-report measures are employed to evaluate characteristics of children and their families that are conceptually and clinically associated with outcome. In addition, results from these assessment measures are designed to reveal therapeutic changes in adjustment over the course of the prevention modalities and through follow-up phases. Evaluation measures are grouped into the following three domains: (a) school measures; (b) child measures; and (c) family measures. Data are collected in these domains at regularly scheduled intervals as depicted in Table 2.

School measures. Teacher reports of children's functioning are an important aspect of evaluation in light of their extensive observations and accuracy in identifying socially 


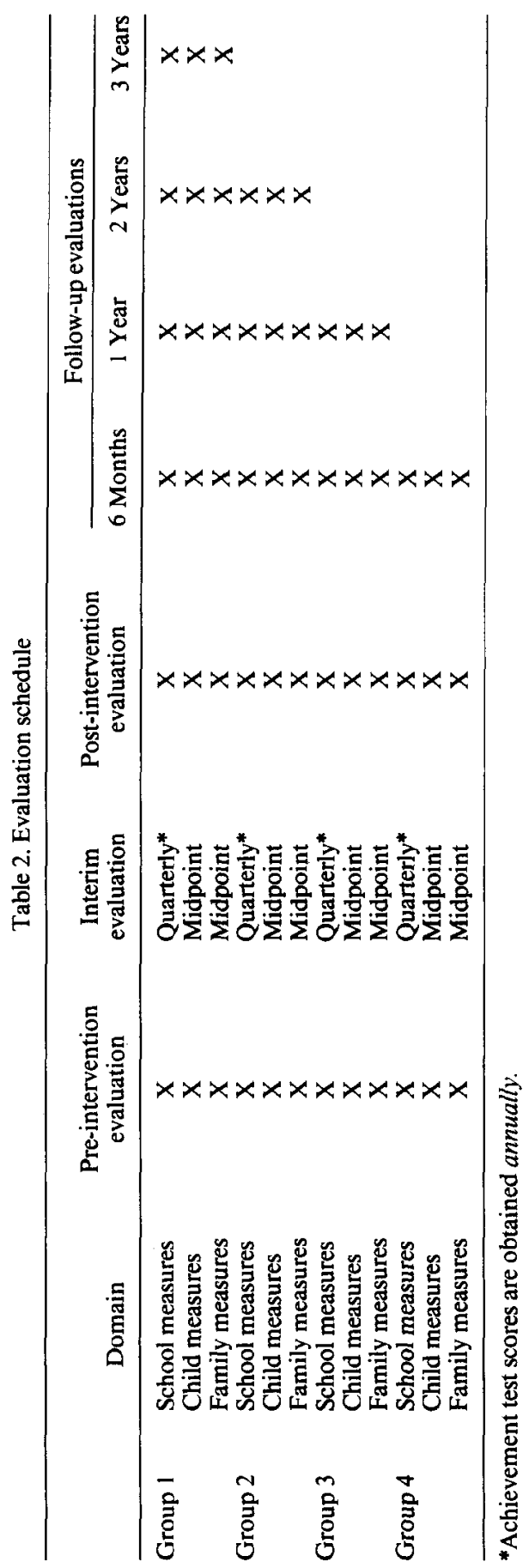


isolated and maladaptive behaviors in children (Achenbach \& Edelbrock, 1986). Teachers of participating children complete an objective measure of children's school problem behaviors and competencies (Teacher-Child Rating Scale; Hightower et al., 1986). In addition, the following information is obtained from student's school records: academic grades, citizenship grades, attendance, suspensions and/or detentions, and achievement test scores.

Child measures. Children are asked to complete several self-report measures that assess drug knowledge and attitudes (Prevention of Child Drug Use Assessment Instrument; Church et al., 1990), anger provocation (Children's Inventory of Anger; Finch, Taylor, \& Nelson, 1987), perceived social networks (Social Support Rating Scale; Cauce et al., 1982), self-esteem (Hare Self-Esteem Scale; Hare, 1975), and perceived control of events (Nowicki-Strickland Internal-External Scale for Children; Nowicki \& Strickland, 1973). In addition, the child's problem solving skills are assessed through their ability to generate solutions to age-relevant problems (Alternative Solutions Test; Caplan, Weissberg, Bersoff, Ezekowitz, \& Wells, 1986).

Family measures. Several dimensions of family assessment are examined to ascertain characteristics that are likely to influence and mediate responsiveness to the prevention strategies on both a short- and long-term basis. A biological parent or other primary caregiver completes a variety of self-report forms that tap: potential stress in the parentchild relationship (Parenting Stress Index; Abidin, 1986), understanding of basic child management skills (Knowledge of Behavioral Principles as Applied to Children; O'Dell, Tarler-Benlolo, \& Flynn, 1979), parenting self-esteem and perceived efficacy (Parenting Sense of Competence Scale; Gibaud-Wallston \& Wandersman, 1978), social satisfaction (Social Provisions Scale; Russell \& Cutrona, 1974), depression (Beck Depression Scale; Beck, Ward, Mendelsohn, Mock, \& Erbaugh, 1961), overall family strengths and weaknesses (Family Assessment Measure-III; Skinner, Steinhauer, \& Santa-Barbara, 1984), modes of dealing with conflict in relationships (Conflict Tactics Scale; Straus, 1979), and parent's report of their child's competencies and problems (Child Behavior Checklist-Parent Form; Achenbach, 1978).

\section{O N C L U S I O N}

Recent statistics document the alarmingly high prevalence of substance use and abuse in adolescents in general, and African-American youth in particular. The majority of programs geared toward prevention of substance abuse in children target knowledge of the effects of illicit substances and drug refusal skills. Moreover, only a handful of such programs have been designed specifically for African-American children. Project SAFE expands upon most existing prevention programs with its emphasis on older peer involvement (Peers as Leaders), concurrent intervention with the family (Parent and Child Training), and simultaneous participation in athletic and cultural activities in the community (Community Activities Program).

Several additional unique features of project SAFE set it apart from other prevention programs. First, it is culturally sensitive to the issues and needs of the African-American children and their families. Arguably, this is an essential feature if drug prevention programs are to be relevant to the experiences of African-American youth (see Kunjufu, 1989). Second, Project SAFE seeks to provide children with alternative activities in addition to teaching drug knowledge and drug refusal skills. A linkage between the 
participants, their families, and the community is critical to the long-term prevention of substance abuse. And third, Project SAFE incorporates ongoing cvaluation of program impact, permitting early identification of children who are having difficulty and allowing for a project response to their special needs.

A pilot version of Project SAFE is currently being conducted in conjunction with the City of Pittsburgh Public Schools. There are 42 children currently participating in SAFE. Families of 25 of these children are meeting, on a weekly basis, with their PACT Counselor.

At this time, anecdotal evidence from caregivers, teachers, and Project SAFE staff suggests a decrease in behavior problems (i.e., less fighting and name calling) and an increase in compliance and prosocial behavior of participating children. For families, the most notable change has been the reduction of stress in the home. The PACT component of Project SAFE has provided an outlet for caregivers to express their personal and familial frustrations and concerns, and to acquire specific parenting skills. The PALS component has been effective in providing high-risk young African-American children instruction in a variety of interpersonal and academic skills from an older peer who serves as a model of social and academic success. Moreover, they have become more aware of high-risk situations and the dangers of drug use.

Taken together, Project SAFE is an innovative, multicomponent program for the prevention of the complex and multidetermined phenomenon of early onset substance abuse. It presently awaits empirical evaluation at the group level to document its shortand long-term impacts.

\section{R E F E R E N C E S}

Abidin, R. R. (1986). Parenting stress index (2nd ed.). Charlottesville, VA: Pediatric Psychology Press.

Achenbach, T. M., \& Edelbrock, C. S. (1983). Manual for the child behavior checklist and revised child behavior profile. Burlington, VT: University of Vermont, Department of Psychiatry.

Achenbach, T. M. (1978). The child behavior profile: I. Boys age 6-11. Journal of Consulting and Clinical Psychology, 46, 478-488.

Albee, G. W. (1982). Preventing psychopathology and promoting human potential. American Psychologist, 37, 1043-1050.

American Association for Protecting Children. (1988). Highlights of official neglect and abuse reporting for 1986. Denver, CO: American Humane Association.

Atkins, B. J., Klein, M. A., \& Mosley, B. (1987). Black adolescents' attitudes toward and use of alcohol and other drugs. International Journal of the Addictions, 22, 1201-1211.

Bandura, A. (1977). Self-efficacy: Toward a unifying theory of behavioral change. Psychological Review, 84, 191-215.

Bandura, A. (1988). Self-regulation of motivation and action through goal systems. In V. Hamilton, G. H. Bower, \& N. H. Frijda (Eds.), Cognitive perspectives on emotion and motivation (pp. 302-317). Dordrecht, Netherlands: Kluwer Academic Publishers.

Bandura, A. (1989). Human agency in social cognitive theory. American Psychologist, 44, 1175-1184.

Barone, V. J., Green, B. F., \& Lutzker, J. R. (1986). Home safety with families being treated for child abuse and neglect. Behavior Modification, 10, 93-114.

Baumrind, D. (1985). Familial antecedents of adolescent drug use: A developmental perspective. In C. L. Jones \& R. J. Battjes (Eds.), Etiology of drug abuse: Implications for prevention. National Institute on Drug Abuse Research Monograph 56. DHHS Pub. No. (ADM) 85-1335. Washington, DC: U.S. Government Printing Office.

Beaulieu, M. A., \& Jason, L. A. (1988). A drug abuse prevention program aimed at teaching seventh grade students problem-solving strategies. Children and Youth Services Review, 10, 131-149.

Beck, A. T., Ward, C. H., Mendelson, M., Mock, J., \& Erbaugh, J. (1961). An inventory for measuring depression. Archives of General Psychiatry, 4, 561-571.

Beck, R. W., \& Beck, S. H. (1989). The incidence of extended households among middle-aged black and white women: Estimates from a 15-year panel study. Journal of Family Issues, 10, 147-168.

Beck, S. H., \& Beck, R. W. (1984). The formation of extended households during middle age. Journal of Marriage and Family, 46, 277-287. 
Bell, P. (1991). The impact of substance abuse on the black community. Psychiatric Letters, 8, 1-4.

Belle, D., Longfellow, C., \& Makosky, V. P. (1982). Stress, depression, and the mother-child relationship: A report of a field study. International Journal of Society and the Family, 12, 251-263.

Berkowitz, N. A. (1982). Community impact: Creating grassroots change in hard times. Cambridge, MA: Schenkman.

Billingsley, A. (1968). Black families in white America. Englewood Cliffs, NJ: Prentice Hall.

Botvin, G. J., Baker, E., Renick, N. L., Filazzola, A. D., \& Botvin, E. M. (1984). A cognitive-behavioral approach to substance abuse prevention. Addictive Behaviors, 9, 137-147.

Botvin, G. J., Batson, H. W., Witts-Vitale, S., Bess, V., Baker, E., \& Dusenbury, L. (1989). A psychosocial approach to smoking prevention for urban black youth. Public Health Reports, 104, 573-582.

Botvin, G. J., \& Dusenbury, L. (1987). Life skills training: A psychoeducational approach to substance abuse prevention. In C. A. Maher \& J. E. Zins (Eds.), Psychoeducational interventions in schools: Methods and procedures for enhancing student competence (pp. 46-64). Elmsford, NY: Pergamon Press.

Botvin, G. J., \& Wills, T. A. (1985). Personal and social skills training: Cognitive-behavioral approaches to substance abuse prevention. In C. S. Bell \& R. Battjes (Eds.), Prevention research: Deterring drug abuse among children and adolescents (pp. 8-49). NIDA Research Monograph No. 63. Washington, DC: U.S. Government Printing Office.

Brooks, J. S., Lukoff, I. F., \& Whiteman, M. (1977). Peer, family, and personality domains as related to adolescents' drug behavior. Psychological Reports, 41, 1095-1102.

Bruno, J., \& Doscher, L. (1979). Patterns of drug use among Mexican-American potential dropouts. Journal of Drug Education, 9, 1-10.

Caplan, M., Weissberg, R., Bersoff, D., Ezekowitz, W., \& Wells, M. (1986). Alternative solutions test: Test manual. New Haven, CT: Yale University.

Carey, K. B., \& Carey, M. P. (1990). Social problem-solving in dual diagnosis patients. Journal of Psychopathology and Behavioral Assessment, 12, 247-254.

Cauce, A. M., Feiner, R. D., \& Primevera, J. (1982). Social support system in high risk adolescents: Structural components and adaptive impact. American Journal of Community Psychology, 10, 227-290.

Center for Disease Control. (1989, September). HIV/AIDS surveillance. Atlanta: Author.

Church, P., Forehand, R., Brown, C., \& Holmes, T. (1990). Prevention of drug abuse: Examination of the effectiveness of a program with elementary school children. Behavior Therapy, 21, 339-347.

Clark, R. M. (1983). Family and school achievement: Why poor black children succeed or fail. Chicago: University of Chicago Press.

Clum, G., Patsiokas, A., \& Luscomb, R. (1979). Empirically based comprehensive treatment program for parasuicide. Journal of Consulting and Clinical Psychology, 47, 937-945.

Cowen, E. L., \& Work, W. C. (1988). Resilient children, psychological wellness, and primary prevention. American Journal of Community Psychology, 16, 59 1-607.

Dawkins, M. P. (1980). Alcohol information on black Americans: Current status and future needs. Journal of Alcohol and Drug Education. 25, 28-40.

Demarsh, J., \& Kumpfer, K. L. (1986). Family-oriented interventions for the prevention of chemical dependency in children and adolescents. Childhood Chemical Abuse, 8, 117-151.

Denicola, J., \& Sandler, J. (1980). Training abusive parents cognitive-behavior techniques. Behavior Therapy, 11, 263-270.

Dielman, T. E., Shope, J. T., Butchart, A. T., \& Campanelli, P. C. (1986). Prevention of adolescent alcohol misuse: An elementary school program. Journal of Pediatric Psychology, 11, 259-282.

Dishion, T. J., Patterson, G. R., \& Reid, J. R. (1988). Parent and peer factors associated with sampling in early adolescence: Implications for treatment. In E. R. Rahdert \& J. Grabowski (Eds.), Adolescent drug abuse: Analyses of treatment research. (pp. 69-93). NIDA Research Monograph 77. Washington, DC: U.S. Government Printing Office.

Dishion, T. J., Reid, J. R., \& Patterson, G. R. (1988). Empirical guidelines for a family intervention for adolescent drug abuse. Journal of Chemical Dependency Treatment, 1, 1988.

Dodge, K. A. (1980). Social cognition and children's aggressive behavior. Child Development, 51, 162-170.

Dodge, K. A., \& Newman, J. P. (1981). Biased decision making processes in aggressive boys. Journal of Abnormal Psychology, 90, 375-379.

Dressler, W. (1985). Extended family relationships, social support, and mental health in a southern black community. Journal of Health and Social Behavior, 26, 39-48.

Elliot, D. S., \& Ageton, S. S. (1980). Reconciling race and class differences in self-reported and official estimates of delinquency. American Sociological Review, 45, 95-1 10.

Field, T. H., Widmayer, S. M., Stringer, S., \& Ignatoff, E. (1980). Teenage, lower-class, black mothers and their preterm infants: An intervention and developmental follow-up. Journal of Social Issues, 36, 6487.

Finch, A. J., Taylor, C. F., \& Nelson, W. M. (1987). Assessment of anger. In R. J. Prinz (Ed.), Behavioral assessment of children and families (pp. 37-55). New York: JAI Press.

Fleming, J. P., Kellam, S. G., \& Brown, C. H. (1982). Early predictors of age at first use of alcohol, marijuana, and cigarettes. Drug and Alcohol Dependency, 9, 285-303.

Forehand, R. L., \& McMahon, R. J. (1981). Helping the noncompliant child: A clinician's guide to parent training. New York: Guilford. 
Forehand, R., Wierson, M., Thomas, A., Armistead, L., Kempton, T., \& Neighbors, B. (1991). The role of family stressors and parent relationships on adolescent functioning. Journal of the American Academy of Child and Adolescent Psychiatry, 30, 316-322.

Gephart, M. A., \& Pearson, R. W. (1988). Contemporary research in the urban underclass. Items. Newsletter of the Social Science Research Council, 42, 1-18.

Gibaud-Wallston, J., \& Wandersman, L. P. (1978, August). Development and utility of the Parenting Sense of Competence Scale. Paper presented at the meeting of the American Psychological Association, Toronto.

Glick, P. (1981). A demographic picture of black families. In H. P. McAdoo (Ed.), Black families. (pp. 212242). Beverly Hills, CA: Sage.

Goldfried, M. R., \& D'Zurilla, P. J. (1969). The behavioral-analytic method for assessing competence. In C. D. Spielberger (Ed.), Current topics in clinical and community psychology. (pp. 109-127). New York: Academic Press.

Hare, B. R. (1975). The relationship of social background to the dimensions of self-concept. Unpublished doctoral dissertation, University of Chicago.

Harper, F. D. (1976). Alcohol abuse and black America. Alexandria, VA. Douglass Publishing.

Harper, F. D. (1988). Alcohol and black youth: An overview. Journal of Drug Issues, 18, 7-14.

Hartup, W. W. (1992). Peer relations in early and middle childhood. In V. B. Van Hasselt \& M. Hersen (Eds.), Handbook of social development: A lifespan perspective (pp. 257-282). New York: Plenum Press.

Hawkins, J. D., Lishner, D. M., \& Catalano, R. F. (1985). Childhood predictors and the prevention of adolescent substance abuse. In C. L. Jones \& R. J. Battjes (Eds.), Etiology of drug abuse: Implications for prevention (pp. 81-104). Washington, DC: National Institute on Drug Abuse (ADM85-1385), 1985.

Hawkins, J. D., Lishner, D. M., Catalano, R. F., \& Howard, M. O. (1986). Childhood predictors of adolescent substance abuse: Toward an empirically grounded theory. Journal of Children in Contemporary Society, 8, 11-48.

Hightower, A. D., Work, W. C, Cowen, E. L., Lotyczewski, B. S., Spinell, A. P., Guare, J. J., \& Rohrbeck, C. A. (1986). The Teacher-Child Rating Scale: A brief objective measure of elementary children's school problem behaviors and competencies. School Psychology Review, 15, 49-58.

Hofferth, S. L. (1984). Kin network, race, and family structure. Journal of Marriage and Family, 46, 791806.

Holden, G. W., Moncher, M. S., \& Schinke, S. P. (1990). Substance abuse. In A. S. Bellack, M. Hersen, \& A. E. Kazdin (Eds.), International handbook of behavior modification and therapy (2nd ed.) (pp. 869-880). New York: Plenum.

Hops, H., Tildesley, E., Lichenstein, E., Ary, D., \& Sherman, L. (1990). Parent-adolescent problem-solving interactions and drug use. American Journal of Drug and Alcohol Abuse, 16, 239-258.

Hunter, A., \& Ensminger, M. (1991). Diversity and fluidity in children's living arrangements: Life course and family transitions in an urban African-American community. Unpublished manuscript, University of Pittsburgh.

Joffe, R. D., Dobson, K. S., Fine, S., Marriage, K., \& Haley, G. (1990). Social problem-solving in depressed, conduct-disordered, and normal adolescents. Journal of Abnormal Child Psychology, 18, 565-575.

Jones, R. L. (1988). Psychoeducational assessment of minority group children: Issues and perspectives. In R. L. Jones(Ed.), Psychoeducational assessment of minority group children: A casebook (pp. 29-54). Berkeley, CA: Cobb and Henry.

Jones, R. T., McDonald, D. W., Fiore, M. F., Arrington, R., \& Randall, J. (1990). A primary preventive approach to children's drug refusal behavior. The impact of Rehearsal-Plus. Journal of Pediatric Psychology, 15, 211-223.

Jorgensen, S. R., King, S. L., \& Torrey, B. A. (1980). Dyadic and social network influences on adolescent exposure to pregnancy risk. Journal of Marriage and Family, 42, 141-155.

Kandel, D. (1975). Stages in adolescent involvement in drugs. Science, 190, 912-914.

Kandel, D. B. (1982). Epidemiological and psychosocial perspectives on adolescent drug abuse. Journal of the American Academy of Child Psychiatry, 21, 328-347.

Kaslow, N. J., \& Rehm, L. P. (1983). Childhood depression. In R. J. Morris \& T. R. Kratochwill (Eds.), The practice of child therapy (pp. 27-52). Elmsford, NY: Pergamon Press.

Kaufman, E., \& Borders, L. (1984). Adolescent substance abuse in Anglo-American families. Journal of Drug Issues, 2, 365-377.

Kellam, S. G., Ensminger, M. E., \& Turner, R. J. (1977). Family structure and the mental health of children: Concurrent and longitudinal community-wide studies. Archives of General Psychiatry, 34, 1012-1022.

Kellam, S. G., Adams, R. G., Brown, C. H., \& Ensminger, M. E. (1982). The long-term evolution of the family structure of teenage and older mothers. Journal of Marriage and Family, 44, 539-554.

King, S. W. (1985) Black females and alcoholism prevention strategies. In R. Wright \& T. D. Watts (Eds.), Prevention of black alcoholism (pp. 65-81). Springfield, IL: Charles C. Thomas.

Kunjufu, J. (1989). A talk with Jawanza: Critical issues in education of African-American youth. Chicago, IL: African-American Images.

Lipscomb, W. B., \& Goddard, L. L. (1984). Black family features and drinking behavior. Journal of Drug Issues, 22, 337-347. 
Losciuto, L., \& Ausetts, M. A. (1988). Evaluation of a drug abuse prevention program. A field experiment. Addictive Behaviors, 13, 337-351.

Lutzker, J. R., Megson, D. A., Webb, M. E., \& Dachman, R. S. (1985). Validating and training adult-child interaction skills to professionals and to parents indicated for child abuse and neglect. Journal of Child and Adolescent Psychotherapy, 2, 91-104.

Maddahian, E., Newcomb, M. D., \& Bentler, P. M. (1988). Risk factors for adolescent substance abuse: Ethnic differences among adolescents. Journal of Substance Abuse, 1, 11-23.

Martin, E., \& Martin, J. M. (1978). The black extended family. Chicago: University of Chicago Press.

Maypole, D. E., \& Anderson, R. B. (1987). Culture specific substance abuse prevention for blacks. Community Health Journal, 23, 135-139.

McAdoo, H. P. (1978). Factors related to stability in upwardly mobile black families. Journal of Marriage and Family, 40, 761-776.

Moskowitz, J. M. (1989). The primary prevention of alcohol problems. A critical review of the research literature. Journal of Studies in Alcohol, 50, 54-88.

National Institute on Drug Abuse (1988). National Household Survey on Drug Abuse: Main Findings 1985. (DHHS Publication No. ADM 88-1565). Washington, D.C.: U.S. Government Printing Office.

Newcomb, M. C., Maddahian, E., \& Bentler, P. M. (1986). Risk factors for drug use among adolescents: Concurrent and longitudinal analyses. American Journal of Public Health, 76, 525-531.

Nezu, A. M., Nezu, C. M., \& Perri, M. G. (1989). Problem-solving therapy for depression: Theory, research and clinical guidelines. New York: Wiley.

Nowicki, S. Jr., \& Strickland, B. R. (1973). A locus of control scale for children. Journal of Consulting and Clinical Psychology, 40, 148-154.

O’Dell, S. L., Tarler-Benlolo, L., \& Flynn, J. M. (1979). An instrument to measure knowledge of behavioral principles as applied to children. Journal of Behavior Therapy Experimental Psychiatry, 10, 29-34.

Oetting, E. R., \& Beauvais, F. (1990). Adolescent drug use: Findings of national and local surveys. Journal of Consulting and Clinical Psychology, 58, 385-395.

Ogbu, J. U. (1986). The consequences of the American caste system. In U. Neisser (Ed.), The school achievement of minority children: New Perspectives (pp. 48-67). Hillsdale, NJ: Erlbaum.

Patterson, G. R. (1982). A social learning approach: Vol. 3. Coercive family process. Eugene, OR: Castilia Publishing Company.

Pentz, M. A., Cormack, C., Flay, B., Hansen, W. B., \& Johnson, C. A. (1986). Balancing program and research integrity in community drug abuse prevention: Project STAR approach. Journal of School Health, 56, 389-393.

Pentz, M. A., Dwyer, J. H., MacKinnon, D. P., Flay, B. R., Hansen, W. B., Wang, E. Y. I., \& Johnson, A. (1989). A multicommunity trial for primary prevention of adolescent drug abuse: Effects on drug use prevalence. Journal of the American Medical Association, 261, 3259-3266.

Poppen, R. (1987). Behavior relaxation training and assessment. Elmsford, NY: Pergamon Press.

Prendergast, M. L., Austin, G. A., Maton, K. I., \& Baker, R. (1990). Substance abuse among black youth. Madison, WI: Wisconsin Clearinghouse.

Reid, J. (1982). Black America in the 1980s. Population Bulletin, 37, 1-37.

Rhodes, J. E., \& Jason, L. A. (1990). A social stress model of substance abuse. Journal of Consulting and Clinical Psychology, 58, 395-401.

Richard, B. A., \& Dodge, K. A. (1982). Social maladjustment problem solving in school-aged children. Journal of Consulting and Clinical Psychology, 50, 226-233.

Rist, R. C. (1970). Student social class and teacher expectations: The self-fulfilling prophecy in ghetto schools. Harvard Education Review, 40, 411-451.

Russell, D., \& Cutrona, C. E. (1984). The Social Provisions Scale. Unpublished manuscript, University of Iowa, lowa City.

Schaps, E., Dibartolo, R., Moskowitz, J., Palley, C., \& Churgin, S. (1981). Primary prevention evaluation rescarch: A review of 127 impact studies. Journal of Drug Issues, 11, 17-43.

Schinke, S. P., \& Gilchrist, L. D. (1984). Life skills counseling with adolescents. Austin, TX: Pro-ed Press.

Schotte, D., \& Clum, G. (1987). Problem-solving skills in suicidal psychiatric patients. Journal of Consulting and Clinical Psychology, 55, 49-55.

Shimkin, D., Shimkin, E. M., \& Frate, M. (Eds.). The extended families in black societies. The Hague: Mouton.

Skinner, H. A., Steinhauer, P. D., \& Santa-Barbara, J. (1984). The family assessment measure: Administration and interpretation guide. Toronto: Toronto Addiction Research Foundation.

Spivak, G., Platt, J. J., \& Shure, M. B. (1976). The problem solving approach to adjustment: A guide to research and intervention. San Francisco: Jossey-Bass.

Stack, C. (1974). All our kin: Strategies for survival in the black community. New York: Harper \& Row.

Stevens, J. H. Jr. (1984). Black grandmothers' and black adolescent mothers' knowledge about parenting. Developmental Psychology, 21, 1017-1025.

Straus, M. (1979). Mcasuring intrafamily conflict and violence: The Conflict Tactics Scales. Journal of Marriage and Family, $\mathbf{4 1}, 75-88$. 
Taylor, R. J., \& Chatters, L. M. (1988). Church members as a source of informal social support. Review of Religious Research, 30, 193-203.

Tienda, M., \& Angel, R. (1982). Determinants of extended household structure: Cultural pattern or economic need? American Journal of Sociology, 87, 1360-1383.

Van Hasselt, V. B., Hersen, M., Whitehill, M. B., \& Bellack, A. S. (1979). Social skill assessment and training for children: An evaluative review. Behaviour Research and Therapy, 17, 413-437.

Watts, T. D., \& Wright, R. (Eds.). (1983). Black alcoholism: Toward a comprehensive understanding. Springfield, IL: Charles C. Thomas.

Weiss, R. (1974). The provision of social relationsips. In I. Z. Rubin (Ed.), Doing unto others. (pp. 270-282). Englewood Cliffs, NJ: Prentice-Hall.

Werner, E. E., \& Smith, R. S. (1982). Vulnerable, but invincible: A study of resilient children. New York: McGraw Hill.

Wilson, M. N. (1989). Child development in the context of the black extended family. American Psychologist, $44,380-385$.

Wilson, M. N., \& Tolson, T. F. J. (1990). Familial support in the black community. Journal of Clinical Child Psychology, 19, 347-355.

Winburn, G. M., \& Hays, J. R. (1974). Dropouts: A study of drug use. Journal of Drug Education, 4, 249 254. 